\section{Discordias categoriales en la literatura sobre la relación entre cine, televisión e historia*}

\section{Conceptual \\ disagreements in the literature on cinema- television-history relationship}

\author{
Claudio Salinas \\ Carolina Kulhmann \\ HANS STANGE
}

\footnotetext{
Este artículo forma parte de los resultados de los proyectos La historia de Chile en el cine de ficción nacional (Fondecyt $\mathrm{N}^{\circ}$ 1160180, 2016-2018) y Discursos históricos en la ficción televisiva chilena (CNCA № 212977, 2016-2017).

** Claudio Salinas, Instituto de la Comunicación e Imagen de la Universidad de Chile (claudiorsm@u.uchile,cl). Hans Stange, Instituto de la Comunicación e Imagen y Facultad de Arquitectura y urbanismo de la de la Universidad de Chile (hstangemarcus@ yahoo.es). Carolina Kulhmann, licenciada en Sociología y realizadora audiovisual de la Universidad de Chile
}

\section{Resumen}

Por diversas razones, las representaciones históricas en el cine y la televisión han adquirido mayor preponderancia en las últimas dos décadas, lo que ha provocado el desarrollo de un gran número de investigaciones acerca de estos materiales audiovisuales. El artículo compara dos corpus literarios, las investigaciones sobre historia en el cine de ficción y los estudios sobre historia en ficción televisiva, con el fin de comprender sus abordajes teóricos, sus enfoques analíticos y reconocer, si es posible, similitudes y campos de convergencia teórica para la comprensión del papel de las ficciones históricas audiovisuales en las sociedades contemporáneas.

Palabras clave: cine; televisión; historia

\begin{abstract}
Historical representations in film and tel-evision have gained greater prominence in the last two decades, which has led to the development of a large number of studies on these audiovisual pieces. This paper compares two literary corpus -research on history in fiction films and studies on history in television fiction series- in order to understand their theoretical and analytical approaches, and recognize, if possible, similarities and theoretical convergences to comprehend the role of historical audiovisual fictions in contemporary societies.
\end{abstract}

Key words: cinema; television; history 


\section{Introducción}

La literatura acerca de las representaciones históricas en el audiovisual ha tenido un amplio desarrollo en las últimas dos décadas. En Chile, así como en otros países latinoamericanos, y en los campos de estudios europeos y anglosajones de la década anterior, la investigación sobre lo histórico en el audiovisual ha proliferado a la par con el aumento de las producciones históricas de la industria audiovisual. No hace falta una revisión exhaustiva de la literatura para constatar este hecho: una simple panorámica nos muestra una gran cantidad de trabajos sobre esta materia. Autores como Pablo Alvira (2011), Elina Tranchini (2011), Deborah Cartmell (2001), José Carlos Rueda (2009), Kepa Sojo (2009) y Mario Ranalletti (2015) en el campo del cine, Steve Anderson (2001), Erin Bell y Ann Gray (2010), Cecilia Alfaro (2013), María Victoria Bourdieu (2012), Ana María Castillo (2012), María del Mar Chicharro (2009) y Jean-Stéphane Durán (2008) en el de la televisión, y Constanza Mujica (2007), Lorena Antezana y Cristian Cabalin (2017-2018), Claudia Bossay (2011), Tzvi Tal (2012) y Evelyn Erlij (2014) en el caso de los estudios en Chile, entre tantos otros, dan buena cuenta de esto.

En muchos casos, tanto la producción fílmica y televisiva como la reflexión teórica acerca del vínculo entre historia y audiovisual tienen como punto de referencia los actos conmemorativos y rememorativos en torno a diversos episodios y procesos de la historia reciente en los países en los que esta explosión historicista ha tenido lugar: la conmemoración del bicentenario de la república en diversos países iberoamericanos, los 40 años del golpe de Estado en Chile, el revisionismo histórico en torno a la Guerra Civil en España y las largas décadas del franquismo, la remembranza del periodo del imperio colonial británico o de la guerra civil estadounidense son solo una acotada muestra del ejercicio de memoria histórica que suscitan a estas producciones. Como señalan Ramírez y Cabalin, para el caso chileno:

\begin{abstract}
Los actos conmemorativos en torno al Bicentenario de la república de Chile en 2010 y en torno al cuadragésimo aniversario del golpe de Estado en 2013 constituyen momentos ejemplares para estudiar las relaciones entre discursos televisivos y discursos sociales a propósito de una materia particular: la historia nacional. Tanto por medio de actos públicos oficiales, actividades académicas, alusiones y reportajes de la prensa escrita y televisiva, actos escolares y, por supuesto, ficciones y narrativas mediáticas, el espacio social de estos años fue saturado por los discursos históricos (2015:55)
\end{abstract}

El crecimiento exponencial de las producciones televisivas y cinematográficas acerca de lo histórico, sin embargo, han sido abordadas de manera desigual desde el campo teórico. Como lo atestiguan trabajos anteriores (Salinas et.al 2013; Salinas y Stange 2018), existen grandes diferencias en el estudio de los discursos históricos en los campos del cine y la televisión, tanto para el caso chileno como para el resto de la literatura latinoamericana. Estas diferencias no son solo cuantitativas (es decir, en la cantidad de trabajos publicados sobre el tema histórico tanto en relación con el cine como con la televisión) sino principalmente de índole cualitativa, es decir, en el modo en que se aborda la relación con la historia y los énfasis conceptuales que se proponen. Hemos advertido que tal tratamiento desigual ha compartimentado los marcos teóricos y categoriales de uno y otro, como si se tratara de ámbitos diferentes, cuestión que es de suyo problemática pues consagra distinciones entre los medios, sus recursos estéticos y sus usos sociales que la literatura reciente comienza a discutir no sin poca divergencia. ¿Cuál es el sentido de estas claras diferencias entre 
la literatura sobre cine-historia, por un lado, y televisión-historia, por el otro?

Se podría esperar, por ejemplo, que los abordajes de la historia en el cine y la televisión mostraran ciertas similitudes toda vez que, tanto el desarrollo de la industria, como de buena parte de la literatura, indican que lo audiovisual tiende a la convergencia, tanto a nivel tecnológico (convergencia de soportes y plataformas de difusión), como a nivel narrativo (convergencia de temas, estructuras discursivas, tránsito de franquicias de un soporte a otro, etc.) e industrial (convergencia en los modelos de negocios, concentración en grandes corporaciones multimediales, recomposición de los medios de difusión, etc.) (Llorens-Maluquer 1998; Salavarría 2010; Scolari et al. 2012). No obstante, en el caso de los estudios conocidos en Chile tales aproximaciones no son constatadas $\mathrm{y}$, por el contrario, se sigue distinguiendo al cine de la televisión como dos medios de expresión y comunicación separados. Estos estudios son, en su gran mayoría, análisis de casos de películas y series que, practicando diferentes tipos de análisis (semióticos, comparativos, de contenido, etc.), ofrecen resultados descriptivos que no se sitúan necesariamente en marcos teóricos más amplios. Podríamos pensar que se trata entonces de un déficit puramente teórico, en el que los estudios (sobre todo los de televisión-historia) tienden a reiterar y autolimitarse a categorías que en la práctica ya no tienen sentido o valor diferenciador, repitiendo viejos esquemas teóricos imposibles de superar cuando el análisis se aplica a la casuística.

Desde otro punto de vista, en cambio, podríamos pensar que, al margen de la convergencia audiovisual, se puede notar que las diferencias entre el abordaje televisivo y cinematográfico de la historia remiten a los órdenes del sentido y la función social de estos discursos, al punto que, si bien ambos compartirían una base común (el lenguaje audiovisual y sus medios técnicos), seguirían, sin embargo, satisfaciendo usos y expectativas sociales dispares. En tal caso, la televisión y el cine harían cosas distintas con los discursos históricos, pues sus representaciones tendrían distintos objetivos en el orden social, lo que explicaría las diferencias y desniveles en el estudio teórico de ambos dispositivos.

Proponemos en este artículo una contrastación entre los estados del arte de los estudios sobre cine-historia y las investigaciones sobre televisión-historia, que identifique núcleos de problemas a partir de los cuales puedan ser repensadas estas relaciones comparativamente. El objetivo del trabajo es comparar ambos corpus con el propósito de establecer algunas interpretaciones acerca del abordaje de lo histórico en estos medios de difusión, por lejos los más importantes de nuestra época y, sin lugar a dudas, los principales difusores (vehículos) del saber histórico para la mayoría de población en la actualidad (White 2010; Ferro 2008). Para tal cometido, describiremos los marcos teóricos de la relación planteada, con el propósito de estabilizar la discusión sobre lo histórico. No intentaremos demostrar una hipótesis en específico, sino que buscaremos proponer una tesis que pueda servir a la articulación de los binomios cine-historia y televisión-historia de manera analítica, como base para una serie de proposiciones acerca de los usos del discurso histórico en el audiovisual. En las siguientes páginas consignaremos los principales trabajos de cada corpus que han circulado en Chile durante las últimas dos décadas, estableceremos los autores de referencia, los 
principales conceptos y operaciones analíticas realizadas y compararemos los rendimientos de ambos corpus en su afán por interpretar las representaciones de la historia.

\section{La historia en el cine}

Desde fines de los años 60, algunos historiadores comienzan a reflexionar sobre la importancia del cine en la representación histórica, admitiendo que es este medio, junto con otros propios de la modernidad (entre ellos la radio y la televisión) son el principal vínculo de las sociedades con el pasado. La discusión entre estos autores, entre los que cabe destacar, junto con Marc Ferro, al sociólogo Pierre Sorlin, y a los historiadores Robert Rosenstone y Hayden White, va a configurar el conjunto central de problemas en torno a la capacidad del cine para representar los discursos históricos.

El primer gran debate será el del valor de las representaciones cinematográficas, que se expresará en torno a dos grandes problemas. El primero, un problema metodológico de la historiografía, refiere al valor de las películas históricas como fuentes documentales. El segundo, ya sobrepasada la discusión estrictamente disciplinaria, trata del estatuto epistemológico de las representaciones históricas en los filmes, especialmente en los de ficción (Sorlin 1985; Rosenstone 1997; Burke 2005; White 2010).

Tanto Sorlin como White discutirán la tendencia inicial (aunque todavía presente) de los historiadores a pensar en los materiales audiovisuales de la misma manera que si fueran fuentes documentales escritas. Lo dice claramente White: "Demasiado a menudo, los historiadores tratan a los datos fotográficos, cinemáticos y de video como si pudieran ser leídos de la misma manera que un documento escrito" (White 2010). Esta analogía es comprensible en el marco del ejercicio historiográfico, acostumbrado a lidiar con documentos escritos y materiales de archivos, pero conllevó una actitud de desconfianza hacia las películas, entendidas en el mejor de los casos como meras ilustraciones del relato histórico. Además, se hizo presente la percepción de una soterrada amenaza al oficio del historiador profesional, quien constata que ya no es él, sino el cineasta, quien tiene el encargo de relatar el pasado. Tal actitud expresa también el desconocimiento que los especialistas en historia tienen de los lenguajes audiovisuales.

Estas cuestiones derivarán rápidamente en una interrogación acerca de la capacidad del cine (y también de la televisión) para representar la historia. Camarero et al. grafican bien esta desconfianza:

\footnotetext{
El cine es, hoy, una forma de representación importante, quizás la más importante a través de su prolongación, la televisión. Pero es muy diferente de la representación escrita: tiene una estrecha capacidad interpretativa, muestra, no sabe ni contar ni explicar. Si vemos, en una primera toma, un hombre que dispara, en una segunda un cuerpo sangriento por tierra, comprendemos que el primero ha matado al segundo, pero no sabemos quiénes son, ni cuál es su relación. El cine da a ver acciones y objetos, habla en el presente, no expresa nociones abstractas tales como causalidad o matices temporales, puede ilustrar el pasado, no poner en perspectiva las conexiones y conflictos entre fuerzas contendientes.

Por eso, no hay una historia cinematográfica, las supuestas "películas históricas» son ya sea ponencias adornadas con imágenes que coinciden más o menos con el texto, ya sea ficciones que tratan libremente un periodo pasado (2008: 27).
}

La pregunta de fondo es aquí, si acaso las películas históricas son capaces de transmitir una 
verdad histórica. El supuesto de esta pregunta -que la función del cine es transmitir estos hechos "tal y como ocurrieron"- será desmontado por distintos autores que investigarán la naturaleza del discurso audiovisual, relacionándolo con la categoría de verosimilitud más que con la de verdad. En efecto, Metz, por solo mencionar un autor entre muchos otros, nos recuerda que el verosímil cinematográfico guarda más relación con ciertas convenciones de género y estrategias retóricas, que con una pretensión científica de objetividad (Metz 1970:17-30).

Esto nos conduce, así, al segundo gran debate que nos concierne, el del carácter discursivo del lenguaje cinematográfico y las condiciones bajo las que representa la realidad. El reconocimiento de que el cine, como lenguaje, construye una representación de lo histórico y no es un mero reflejo de la realidad histórica queda establecido por Sorlin:

Los historiadores saben hoy -no desde hace mucho
tiempo, ni han agotado las consecuencias de este cambio
de perspectiva- que no abordan una sociedad ajena o
lejana, tal como es, sino tal como se dice. Los textos no
son tajadas de la vida; son discursos construidos según
reglas estrictas, cuya no observancia haría pasar lo escrito
de la condición de texto a la condición de sucesión de
palabras sin destinatario. Las secuencias audiovisuales
parecerían escapar de los límites que se han puesto a los
textos, puesto que cualquier serie de imágenes podría
constituir un film y producir un efecto. Sin embargo, esto
no ocurre así en la práctica (1985: 250).

Y agrega: "los filmes no son simples repertorios de lo visible. En el marco relativamente estrecho que es el de las perspectivas de expresión y de comunicación en cierta época, intervienen permanentemente modificaciones, desplazamientos, reevaluaciones" (Sorlin 1985: 251).

En ese mismo sentido, White afirma que cuando se "usan" las imágenes se debe entender que estamos ante un discurso con "derecho propio, mediante el cual podríamos ser capaces de decir algo diferente de lo que podemos decir en la forma verbal" (White 2010: 218), agregando más adelante que las "secuencias de tomas y el uso del montaje o primeros planos pueden ser hechos para predicar tan efectivamente como las frases, las oraciones, o secuencias de oraciones en el discurso hablado o escrito" (White 2010). Krieger y Tranchini (2009), por otra parte, relevan la contribución de Rosenstone en el reconocimiento del cine como un lenguaje en propiedad que construye unas representaciones del pasado bajo sus propias reglas y códigos discursivos:

(...) su mayor contribución es la de entender el cine histórico como un relato donde se construye la Historia, donde se agitan las mismas problemáticas que en derredor de cualquier discurso histórico. Rosenstone afirma que el cine no refleja la historia, sino que la crea, no refleja la realidad, sino que la construye en base a los criterios de la sociedad que produce una determinada cinematografía, por lo que las películas deben ser analizadas en relación al contexto histórico en el que surgen (2009: 3).

Pero la exigencia de verdad en las representaciones cinematográficas también será tensionada desde el campo de la propia historiografía, que revisará en los últimos años el estatuto discursivo de la propia historia acerca de los acontecimientos del pasado. Como asevera Sorlin (2005), por sobre sus pretensiones explicativas y su apego a una verdad definida disciplinariamente, la historia es, como el cine, un relato sobre el pasado, es decir, una narración elaborada bajo un conjunto específico de reglas, géneros textuales y estrategias retóricas:

Una obra histórica debe ser escrita, lo que supone el uso de un mínimo de elementos retóricos. En la mayor parte de los casos, la obra estudia un periodo, y establece entonces un punto de partida y un punto de llegada. (...) 
El historiador es un narrador y, en cuanto se asoma a una evolución (guerra, crisis, biografía), contrasta momentos de aceleración (batalla, derrota, agravamiento del desempleo) con momentos de calma. Así, en lugar de criticar las películas, los historiadores harían mejor en sondear su propia práctica y, sobre todo, en preguntarse si, lejos de ser un simple medio, el relato no ha sido $-y$ no sigue siendo- la forma esencial para aprehender $y$ representar el mundo (2005: 23-24).

Este desplazamiento en las bases epistémicas de la discusión sobre historia y cine configurará los límites del tercer debate de importancia en este campo: cómo se articulan las interacciones entre lo cinematográfico y lo histórico en tanto que dos campos discursivos. Al asumir que tanto la historia como el cine producen representaciones del pasado, el problema a plantear es cómo éstas convergen, se contraponen e influencian mutuamente en el proceso de construcción del imaginario de una época pasada. Como dirán Rueda y Chicharro:

\footnotetext{
Como es sabido, el concepto de representación, desde un punto de vista etimológico, tiene una doble acepción: la de ausencia (la representación es el objeto que sustituye a lo representado) y la de presencia (imagen sustitutiva con sentido simbólico). El cine por definición expresa doblemente este carácter. En primer lugar, como escenificación filmada. En segundo término, como representación de prácticas y usos sociales externos al film. Desde una perspectiva histórica, muchas veces, hemos de hablar, incluso, de un tercer nivel de representación, puesto que el film expresa acontecimientos ya sucedidos (2004: 429).
}

Discurso y representación, por tanto, referirían a las formaciones o cuerpos de conceptos y prácticas de sentido mediante las cuales damos forma a lo real, disputamos su significación y narramos sus contornos. Cine e historia son campos discursivos adyacentes, con lógicas propias que producen representaciones diferentes de los mismos hechos sociales. Evidentemente se establecen relaciones entre estos campos, pero esto no implica que ambos sean conmensurables o que uno sea reductible al otro (White 2010).

La gran cantidad de literatura generada en el marco de este debate aborda innumerables casos de películas históricas que son revisadas ya sean en el contexto de los cines nacionales, ya bajo la perspectiva del estudio de sus estructuras narrativas o del análisis de los componentes históricos de su discurso. De este debate, junto a la literatura que aborda las demás cuestiones reseñadas más arriba, se desprenden nítidamente tres líneas secundarias de trabajo: 1. El estudio de las representaciones que el cine hace de los hechos históricos, su intención y relevancia social; 2. Los usos del cine como herramienta didáctica para la enseñanza de la historia; y 3. La validez del material fílmico como fuente y recurso para la investigación histórica.

La primera de estas líneas, que podemos denominar como representaciones cinematográficas de hechos históricos, es, sin lugar a dudas, la más explorada por las investigaciones que destacan que los géneros épico e histórico tendrían la capacidad de "recrear" y referirse directamente a la realidad en un periodo o proceso histórico acotado. Esta vertiente ha enfatizado en ciertos discursos con carga identitaria (Martín-Barbero 1991) y se ha referido a cuestiones tales como la representación de la historia antigua (Uroz 1999), la historia de Estados Unidos en el cine de Hollywood (Rubio 2010; Nigra 2010; Nigra 2012) la historia reciente de Argentina (Piccinelli et.al 2012: 171-195), la historia de la Guerra Civil y el franquismo en España (Ruzafa 2004; Romero 2002) la historia mexicana (Jablonska 2009) y la Revolución Rusa (Tranchini 2011), etc. 
Para el caso chileno, sin embargo, conocemos pocos trabajos que aborden las representaciones cinematográficas de la historia, siendo quizás los más señeros los de Raurich y Silva (2011), Vásquez (1986), Bossay (2010), Rinke (2002), Del Alcázar (2013) y Salinas y Stange (2017).

La segunda línea -usos del cine en la didáctica de la historia- entiende las representaciones audiovisuales aún como ilustraciones de los procesos históricos; esto quiere decir que el cine se considera en relación mimética con la realidad. Nociones como estas se pueden encontrar en los textos de Zunzunegui (2002), Ferro (2008), Jakubwicz y Radetich (2006), Camarero et al. (2008) y Caparrós (2007:). La tercera línea, que concibe al cine como fuente histórica, lleva adelante las discusiones más propias de los métodos historiográficos en relación al cine, como atestiguan los textos de Alvira (2011), Bloch (1995), Laguarda (2006:109-119), Guynn (2006), Romano (1998) y Pelaz (2007).

El primer aspecto notable de esta revisión es que, si bien existe mucha literatura sobre el tema, toda ella gira en torno a los planteamientos principales de los autores señalados al comienzo (Ferro, Sorlin, Rosenstone y White, principalmente). Es decir, son numerosos los trabajos, pero todos refieren a un debate establecido según los puntos reseñados, que constituyen realmente el núcleo conceptual de la discusión cine-historia, sin agregar nuevos desarrollos teóricos. La evidencia es patente en la literatura revisada: a pesar de que existe un sustrato de términos y discusiones medianamente establecido y delimitado, la discusión no alcanza a avanzar en lo que respecta a nuestro conocimiento de la relación historia-cine, pues la gran mayoría de los trabajos presenta estudios de caso, en los que se aplican las categorías de Sorlin o Ferro, pero no se las discute realmente. Habría que puntualizar, además, que cada autor adapta las categorizaciones existentes a las condiciones particulares de los casos analizados, generando taxonomías y clasificaciones operativas de lo histórico que no logran compararse entre sí, no se aproximan teóricamente ni permiten generalizaciones.

Así, por ejemplo, las categorizaciones de Ferro (2008) no se condicen con las elaboradas por Rosenstone. El primero, divide los géneros históricos entre ficciones históricas, donde las necesidades estéticas priman frente el «rigor» de los sucesos, y reconstrucciones históricas, donde se despliega de forma manifiesta un discurso sobre el pasado. Rosenstone (1997), por otro lado, elabora las categorías de historia como drama, donde a partir de la ficcionalidad narrativa se delimita un período histórico concreto, y la de historia como experimentación, donde el discurso intencional de un cineasta genera rupturas, en un mismo gesto, con las formas de representación de lo histórico cinematográfico y con los propios sentidos comunes sobre un personaje, evento o período. Por otra parte, José María Caparrós (2007) distingue entre películas con valor histórico/sociológico, esas que se transforman en testimonios de las mentalidades del período de su producción; las de género histórico, que evocan a eventos y personas reales que fueron más o menos relevantes en el pasado; y las de intencionalidad histórica, donde lo relevante se encontraría en ese discurso que intenta hacer historia sobre el pasado. Por último, Monterde et al. (2003) han propuesto las categorías de ficciones de época, donde los períodos del pasado son telones de fondo para una narración que podría acontecer, en 
lo sustancial, en cualquier contexto; ficciones históricas documentalizadas, donde son los eventos y/o personajes históricos los que estructuran el relato; $y$, por último, el ensayo histórico ficcional, donde, nuevamente, lo que comparece es esa individualidad que propone un discurso histórico pleno y que provoque un conocimiento histórico en el espectador.

\section{La historia en la televisión}

En años recientes se ha conocido en Chile una prolífica cantidad de estudios de casos que analizan la presencia de lo histórico en distintos formatos televisivos. Los trabajos de Constanza Mujica (2007), Lorena Antezana y Javier Mateos (2015), María de los Ángeles Rodríguez (2004) y Christian Miranda (2010), solo por nombrar algunos, dan cuenta de la reciente preocupación por la relación historiatelevisión. Pero, a diferencia de lo que ocurre en la literatura sobre historia y cine, la relación entre los discursos históricos y los televisivos no cuenta con un núcleo de autores y problemas tan nítidamente asentados. La abundancia de casos analizados carece aún de un contexto teórico que permita comprender dicha relación de manera más profunda.

Varias razones pueden explicar esta carencia. En primer lugar, podemos mencionar el desprecio recurrente del que la televisión ha sido objeto como tema de investigación: en efecto, comparada con las bellas artes, la literatura o el propio cine, la televisión no ha gozado del favor de los intelectuales que la han considerado, por mucho tiempo, un objeto cultural de menor valía, cuyo estudio no reviste interés porque se trata, en el mejor de los casos, de simple espectáculo y vana diversión al que no se ha de poner mayor atención o, en el peor de los casos, de una pura reproducción mercantil de la sociedad de consumo. Cuando algunos pensadores la han tomado en serio, la mayor parte de las veces es para denunciar sus poderes alienantes $y$ estereotipadores, señalándola como enemiga de la cultura y, por tanto, negándola. (Williams 2011; Adorno 1966, Otero y López 1993).

Una segunda razón para explicar la ausencia de discusión teórica en la relación historiatelevisión es que, a diferencia del cine, las representaciones históricas televisivas no han sido aún objeto de interés de la comunidad de historiadores, por lo que buena parte del debate acerca de cómo la televisión representa la historia se ha dado en los espacios de la prensa, del debate público político y mediante la intervención de voces opinantes que no son necesariamente expertos en historia ni en televisión. El resultado de esto es que la discusión vuelve constantemente sobre ciertos problemas normativos, especulativos o retóricos que son auténticos caminos sin salida para la teorización. Entre ellos, la discusión acerca de si determinado programa televisivo representa realmente lo que fue el acontecimiento histórico (como si la televisión fuera un medio transparente para reflejar la realidad y la historia fuera un discurso unívoco y prístino, construido en torno a una verdad inequívoca acerca del pasado). También los debates acerca de la corrección de la historia contada en televisión y sus usos para la enseñanza y la educación de públicos masivos; las exigencias de veracidad histórica que suponen una función que la televisión no tiene; los reclamos sectaristas por la "sobrerrepresentación" de tal o cual historia; la reducción de las representaciones históricas a la "intención" del autor o los "intereses" de tal o 
cual avisador o la simplificación de los "efectos" del relato histórico televisivo en términos de simple información transmitida (didactismo) o mera reacción provocada (polemismo).

La comunidad de los investigadores en comunicación es, por tanto, la que en la práctica ha abordado esta cuestión como parte de sus preocupaciones en torno al medio televisivo, poniendo énfasis en este último componente de la relación, sin una mayor reflexión acerca de los aspectos propiamente históricos. En este contexto, el marco del estudio sobre las representaciones de la historia en la televisión es el mismo que el del resto de los estudios sobre representaciones televisivas: el conjunto de las teorías generales sobre los medios de comunicación. Como es sabido, las investigaciones sobre el discurso televisivo, tanto en Chile como en España, Estados Unidos, el Reino Unido y otros países, siguen de cerca los postulados teóricos de las teorías generales de la comunicación, al punto de que éstas son indistinguibles de lo que podríamos llamar una "teoría de la televisión" (Vilches 1993; Vilches 1997; González Requena 1995; Fiske 2001, Fiske y Hartley 2004).

En este ámbito se reconocen la dimensión industrial de su producción, la racionalidad mercantil de su desarrollo y la influencia social de sus discursos, pero no se construye nunca una teoría sobre el medio y su inscripción en los discursos sociales. Así, por ejemplo, cuando Wolf $(1985 ; 1992)$ recapitula las teorías sobre los efectos de los medios y sus funciones en la sociedad (manipulación, control social, reproducción cultural, etc.) las afirmaciones que realiza aplican indistintamente a los discursos televisivos, así como a cualquier otra forma de discursividad mediática, sin reconocer sus atributos específicos. De esta suerte, la televisión parece ser el medio "por defecto" en el que se desenvuelven algo así como los "discursos mediáticos". También, para la mayor parte de la literatura anglosajona, el estudio de los discursos televisivos es indistinto del estudio de los efectos del medio televisivo y de los medios de comunicación en general (Hartley 2008; Butler 2002; Holland 2000).

En consecuencia, los estudios sobre el discurso histórico en la televisión siguen los mismos caminos que los de otros análisis de representaciones televisivas. Ante la falta de un marco teórico propio y específico, tienden a primar los enfoques tecno-metodológicos por sobre las decisiones teóricas. Es decir, encontramos una gran cantidad de estudios de casos sustentados en análisis de contenidos, en análisis semiológicos, en estudios de audiencias $\mathrm{o}$ en investigaciones sobre el enmarcamiento $\mathrm{o}$ los efectos de alcance medio de dichas representaciones y sus consecuencias cognitivas o conductuales. Grosso modo, podemos afirmar que los estudios sobre la relación historia-televisión han tomado dos enfoques metodológicos principales: 1) establecer las proposiciones de sentido de los discursos televisivos sobre tópicos históricos (Antezana 2015; Mujica 2007; Castillo et.al. 2012, Mateos y Ochoa 2016, Rueda 2009, entre ellos), o 2) estudiar su relación con el contexto y determinar las funciones sociales que cumplen los discursos históricos televisivos (Cabalin y Ramírez 2015, Antezana y Mateos 2015, Santa Cruz 2018, Jarpa 2017, entre otros). Tal como sucede con otras teorías sobre los procesos comunicativos, los estudios sobre los discursos televisivos suelen repetir esquemas analíticos desarrollados hace décadas, acumular casos de los que no se extraen ideas comprensivas o 
segmentar el fenómeno en distintas áreas que no siempre logran complementarse.

¿El sentido de esta dispersión casuística es el mismo que en el de la casuística acerca de la relación cine-historia que referimos en el apartado anterior? Ciertamente no, pues si en el ámbito del cine los trabajos sobre casos se solventan en una reproducción de los debates teóricos desarrollados por Ferro (2008), Sorlin $(2005,1985)$ en el ámbito de los estudios sobre televisión e historia, los casos analizados recurren expeditamente a un repertorio de problemas típico de los estudios sobre televisión que no tienen entre sí directa relación ni organicidad, salvo el común denominador del propio dispositivo televisivo, a saber: la incidencia de las representaciones televisivas en la construcción de memorias e identidades colectivas, la proximidad de los discursos televisivos con las representaciones de la experiencia cotidiana, la preeminencia y especificidad de los formatos y géneros televisivos en la representación de los discursos sociales y su alto impacto en la esfera de las prácticas sociales, incluso más que en el de las construcciones discursivas propiamente tales.

De lo anterior se sigue que la mayoría de estos estudios de caso ponen su atención en las operaciones del medio televisivo y no en las representaciones históricas mismas. ¿Cómo se elabora, entonces, lo histórico en las ficciones televisivas? Estas recogen los elementos históricos presentes en diferentes matrices culturales, no sólo del saber historiográfico, sino también del folclor popular, de las mitologías, de la memoria colectiva, de las festividades conmemorativas, de los conocimientos escolares, etc. Estas matrices han de ser ya reconocibles como parte de los sentidos comunes imperantes y de la cultura colectiva de los públicos. En este sentido, las ficciones televisivas no recurren a un relato histórico coherente y cerrado, sino a un conjunto de retazos más o menos organizados, variables, en distintas versiones, en el que se mezclan elementos residuales y emergentes, en el que conviven explicaciones de procesos generales o sociales con elementos o percepciones individuales, emocionales o simplemente pintorescas o anecdóticas: la historiografía en vínculo aproblemático con la trivia.

Por esta razón, los discursos televisivos se difuminan en medio de la discursividad social, a la vez que mediatizan discursos sociales ya elaborados; se ven afectados inmediata y directamente por las determinaciones de otros regímenes institucionales y las funciones que éstos les imponen: modas, temas del momento, sentidos comunes, acontecimientos públicos, controversias, etc. Esto quiere decir que no hay en la televisión ningún discurso histórico, político, moral, artístico, etc.- que le sea "propio" en un sentido estricto, todos sus discursos provienen ya del contexto social. Esta indistinción entre los discursos televisivos y el resto de los discursos sociales es la principal cualidad y fortaleza de la televisión, es la condición que explica su importancia capital en la experiencia cotidiana de las personas durante las últimas seis décadas y nos permite vislumbrar el rol clave que el discurso televisivo tiene como agente conformador y articulador de la sociedad. Al mismo tiempo, esta indistinción es el principal obstáculo que enfrentan los analistas al momento de intentar describir unidades de estudio, categorías de investigación, y rasgos propios de lo televisivo. La familiaridad del espectador con el mundo imaginado en la ficción televisiva, a partir de elementos históricos, 
confirma, por una parte, el repertorio de saberes sobre la historia ya válidamente establecidos en los sentidos comunes, y legitima, por otra, el orden social fundamental que acredita dicho conjunto de saberes.

Las ficciones televisivas recrean estos elementos y los reelaboran mediante los procedimientos y formas de los géneros televisivos, especialmente los melodramáticos. Los elementos históricos serían recogidos de forma fragmentaria, esquemática y a veces incoherente 0 simplificada, y "rellenados" o vinculados con un repertorio de otros elementos tomados, ya de los sentidos comunes hegemónicos, ya de los propios recursos narrativos y estilísticos del medio. Así, la ficción histórica televisiva es un dispositivo con un fuerte efecto de realidad, producido por medio de un estilo y un formato audiovisual reconocible por los públicos, expertos en interpretar la lucha del bien y el mal, la oposición entre el deber y el amor, el fondo de justicia o injusticia de una acción, etc.

Constanza Mujica, a modo de ejemplo, estudia el repertorio de telenovelas chilenas producidas entre las décadas de 1990 y 2000, situadas en marcos históricos reconocibles, afirmando que estas producciones:

(...) se instalan como una visualización de la historia oficial del país, pero con códigos fuertemente melodramáticos y unos héroes retratados desde lo doméstico. De hecho, el foco de la narración está en sus biografías, con un énfasis en su micro-relato personal y privado como eje de articulación del devenir histórico en el que participa (...) La ficción melodramática sugiere alternativas posibles, ocupando los vacíos de las historiografías que no puede imaginar-o solo parcialmente-, por ejemplo, sentimientos y afectos. Esto, sin duda, permite una conexión con los públicos (2007:22)

El formato organiza la estructura narrativa del discurso televisivo, da pauta para organizar las relaciones entre los personajes y el desarrollo de los conflictos, segmenta la historia en unidades seriadas y reconocibles, cotidianiza las relaciones afectivas, inserta las marcas históricas y pone de relieve los aspectos llamativos, sean estos los anacronismos epocales o las dimensiones psicológicas de los personajes (Rueda 2009).

¿Qué hace, entonces, la televisión con los discursos históricos? Proponemos que, para el caso televisivo, un enfoque apropiado para entender el problema es emplear la categoría de mediación, que permite visibilizar el desplazamiento que el medio televisivo operaría desde el problema de la representación de lo histórico hacia el problema de los usos sociales de lo histórico. En otras palabras, no se trata aquí de la interacción entre dos campos discursivos (como en el caso del histórico y el cinematográfico), sino de las negociaciones de sentido entre múltiples campos -historia, memoria, sentido común, vida cotidiana, etc.- que son reelaborados por los formatos televisivos en articulación con los usos sociales contingentes.

La idea de mediación es útil para comprender las intrincadas relaciones entre los discursos sociales y los discursos históricos televisivos. Por una parte, sobrepasa la concepción tradicional del medio como un acicate para obtener respuestas prefiguradas en la audiencia, y la crítica habitual de la televisión como un mero reflejo de la estructura social y sus estereotipos. Martín-Barbero reconoce como mediaciones los espacios físicos y simbólicos -"la cotidianidad familiar, la temporalidad social y la competencia cultural" (Martín-Barbero 1991:233) - en los que se producen, de manera preferente, unas interrelaciones entre diversas matrices cultura- 
les, entre agentes productores y consumidores, entre discursos hegemónicos y subalternos, etc. En estos espacios, la interrelación promueve apropiaciones, resignificaciones, identificaciones y negociaciones de sentido que transforman los discursos vehiculizados por estos agentes y legitimados en dichas matrices. La mediación no es el efecto del medio sobre el individuo o sobre la sociedad: es la transformación de los significados culturales que ocurre cuando los públicos se apropian de los mensajes mediáticos ( $\mathrm{y}$ de los mensajes sociales en general) y los interpretan de acuerdo a sus condiciones y matrices culturales (MartínBarbero 1991).

La organización de los sentidos históricos en la mediación televisiva vincula directamente los fragmentos de los relatos históricos con la experiencia cotidiana de los espectadores. Esta experiencia, hecha de sentido común y de vivencias (cuyos saberes provienen de las más diversas índoles), influye en el sentido histórico arrancándolo del tiempo pasado e incorporándolo en el presente de la cotidianidad, siempre contingente y actualizada. Tal "historia siempre presente", la del relato ficcional televisivo, encuentra su sentido en la experiencia del espectador y no en su correspondencia con un mundo mítico, narrativo, verosímil, pasado. La historia no es la explicación del tiempo anterior, 0 de los orígenes de un proceso social o colectivo, sino que es un elemento más, significativo, del repertorio interpretativo con que cuenta el individuo para entender su presente.

Los realizadores de televisión, que no son historiadores de formación, recurren entonces a las fórmulas históricas del sentido común porque ellas alimentan, en primer lugar, su propia relación con la historia. El efecto de realidad de las series televisivas se lograría por medio de una correspondencia entre lo representado y lo previamente admitido como "histórico" por parte de las audiencias: comunidades interpretativas que verifican el cumplimiento de sus expectativas y el orden de cosas que ya conocen. En este sentido, las ficciones históricas en televisión no aportan al conocimiento de la historia en términos de fechas, procesos, acciones, antecedentes, fuentes (es decir, de "información historiográfica"), sino que ofrecen una narrativa que explica la historia a partir de relaciones interpersonales, valores universales (patriotismo, valentía), costumbres o experiencias compartidas, reforzando el lazo entre los elementos históricos del saber compartido por un grupo social y los significados a partir de los que se organiza la experiencia cotidiana de los individuos.

\section{Dos miradas (acerca de la historia) que no se cruzan}

La literatura sobre los discursos históricos en el cine ha desarrollado un conjunto de problemas proveniente del debate historiográfico acerca de las representaciones del pasado en los filmes. Este conjunto de problemas, diseminado en una extensa cantidad de trabajos sobre casos acotados, se encuentra la mayor parte de las veces restringido o limitado por la diversidad de categorías y aproximaciones analíticas que estos mismos casos manifiestan, dificultando el ejercicio de comparación y la consecución de ulteriores desarrollos teóricos acerca de la relación historia-cine.

La literatura sobre las representaciones históricas en las ficciones televisivas, en cambio, 
hacen propio un conjunto de problemas e hipótesis acerca del medio televisivo que provienen principalmente del campo de estudios de la comunicación antes que de la historiografía. La gran cantidad de estudios de casos, que también se constatan en este ámbito, aborda el problema desde predicamentos técnico-metodológicos antes que teóricos, enfrentando una serie de cuestiones que atañen más a la discusión acerca de las relaciones entre los discursos televisivos y los discursos sociales que a una problematización de la historia respecto de la televisión.

¿Cómo es posible, entonces, comparar ambas literaturas? $\mathrm{Si}$, como planteamos al comienzo de este artículo, seguimos la premisa de que las representaciones históricas en el cine y la televisión tienden a converger en la medida que, por una parte, comparten elementos basales del lenguaje audiovisual y, por otra, se articulan en esquemas productivos y de circulación globales, deberíamos admitir que entre los campos de estudios cinematográficos y televisivos existe un desequilibrio teórico. La tendencia al estudio de casos en ambos campos ha dificultado el desarrollo de marcos teóricos comprensivos, de categorías de análisis comunes y de enfoques metodológicos ampliamente aceptados que permitan desarrollar hipótesis explicativas acerca de las relaciones cine-historia y televisión-historia. En lugar de esto, la abundante acumulación de casos ha conducido a repetir formulaciones teóricas ya conocidas, llegando a conclusiones previsibles, de las que es difícil inferir proposiciones teóricas de conjunto.

Sin embargo, en virtud de la revisión que hemos realizado, advertimos que el cine y la televisión hacen cosas diferentes con los discursos históricos, de lo que necesariamente se colige que no podemos comparar ambos campos de estudio con ligereza. Desde esta perspectiva, la cuestión no es solamente constatar un desbalance entre ambos campos de estudio, o un desajuste entre los rendimientos de uno y otro. Pese a que el cine y la televisión puedan compartir un lenguaje y una base técnica común, los usos sociales de ambos y las interrogantes que se plantean respecto a lo histórico en el terreno de la representación audiovisual, son muy distintas. ¿Cómo sobreponerse a esta supuesta desarticulación teórica? ¿Es necesario acercar ambos corpus analíticos? Puede parecer procedente este camino, solo a condición de no advertir las diferencias que la literatura exhibe entre los abordajes de lo histórico en el cine y la televisión. Desde este ángulo, el problema no parece ser la consolidación de ambos corpus en una especie de "canon literario" acerca de las representaciones históricas, sino un reconocimiento adecuado de las particularidades de cada medio en su empleo del lenguaje audiovisual y, sobre todo, de su relación con la sociedad. En este aspecto, urge sobre todo reconocer la importancia de las representaciones televisivas de la historia en la configuración de las experiencias actuales de la sociedad respecto del pasado.

En el mismo sentido, ¿parecería apropiada una asimilación teórica para analizar las producciones televisivas? ¿O se debe forzar una homologación metodológica para permitir que los resultados de los estudios sean comparables? No parece ser tampoco este el camino. Emprender estudios de caso sobre la recepción cinematográfica de los filmes históricos, o construir categorías de análisis sobre la base de las ideas de Sorlin o Ferro para estudiar casos de series históricas de televisión homologaría artificialmente las diferencias 
que ambos campos reconocen al construir su conocimiento casuístico sobre la producción audiovisual, a la vez que escamotearía las distintas funciones y problemas que la interrogación teórica ha advertido en cada campo. Interpretaciones acumulativas acerca de los casos, mediante una estandarización categorial, parecen no ser la vía adecuada para ahondar en una reflexión teórica que reclama, en cambio, preguntas sobre la potencialidad de ambos medios para imaginar el pasado y construir puentes entre él y las configuraciones presentes de la realidad social.

¿Debemos entonces evitar los ejercicios categoriales, demostrada su futilidad para este problema? ¿Deberíamos desistir de la casuística para promover una reflexión más general acerca de la relación entre discursos históricos y representaciones audiovisuales? Tal desistimiento desaprovecharía los hallazgos de las investigaciones realizadas hasta ahora, tanto en el ámbito del cine como de la televisión. El corto rendimiento teórico de una parte importante de los estudios no desacredita los resultados obtenidos hasta la fecha, precisamente por el detallado conocimiento obtenido de las producciones audiovisuales. Esta situación impone más bien una exigencia de profundización reflexiva, que se sobreponga a la particularidad del caso (sin desestimarlo) y encuentre conexiones entre él y problemas de orden más general (sin homogenizarlos).

¿Deberemos, así, buscar nuevos puntos de partida para el debate? Quizás la necesidad real es la de avizorar alternativas para el trayecto de estos campos deestudio, puntos dellegadaantes que nuevas partidas, en las que cine y televisión converjan para explicar el recurso a una historia audiovisual de las sociedades contemporáneas, pero también se distancien para comprender el contexto y situación en el que dichas historias audiovisuales construyen y producen el sentido del pasado. Un debate que, lejos de agotarse en la paciente enumeración de las similitudes y diferencias de tal o cual caso con algún otro, avance sobre la interconexión de los saberes de la historia, la estética y la comunicación, es decir, avance interdisciplinariamente en el conocimiento sobre lo que el cine y la televisión hacen con la historia.

\section{Bibliografía}

Adorno, Th. 1966. Televisión y cultura de masas. Córdoba: Eudecor - Editorial Universitaria de Córdoba.

Alfaro Gómez, Cecilia. "La telenovela de época: ¿Resultado de la ideología revolucionaria?" Payaso Procaz. Cultura sin pudor, no. 4 (2013).

Alvira, Pablo 2011. "El cine como fuente para la investigación histórica. Orígenes, actualidad y perspectivas." Páginas 3 (4): 135152.

Anderson, Steve 2001. "History TV and Popular Memory". Television Histories: Shaping Collective Memory in the Media Age. Gary R. Edgerton y Peter C. Rollins (Eds.). Lexington: University Press of Kentycky. 19-36

Antezana, Lorena 2015. Las imágenes de la discordia. La dictadura chilena en producciones televisivas de ficción. Buenos Aires: CLACSO.

Antezana, Lorena y Cristian Cabalin 2017-2018. "El precio del consenso. La dictadura en la ficción televisiva chilena de la conmemoración de los 40 años del Golpe de Estado." Chasqui. Revista Latinoamericana de Comunicación. 136: 249-262.

Antezana, Lorena, Mateos, Javier 2015, "Ficción televisiva e historia reciente: el caso de los archivos del cardenal". XI Jornadas de Sociología. Universidad de Buenos Aires: Facultad de Ciencias Sociales: 13-17.

Bell, Erin y Ann Gray (Eds.) 2010. Televising History. Mediating the Past in Postwar Europe. Londres: Palgrave Macmillan.

Bloch, Avital 1995. "Sobre el cine, la historia y las nuevas 
posibilidades de la verdad". Estudios sobre las culturas contemporáneas. 5: 53-67.

Bourdieu, María Victoria 2012. "Memoria social y ficción televisiva. Contexto político de la mirada al pasado." AsAECA 2012 III Congreso Internacional de la Asociación Argentina de Estudios de Cine y Audiovisual. Buenos Aires

Bossay, Claudia 2010. "Representaciones de pasados conflictivos: Aspectos teóricos de la memoria e historiofotía en filmes chilenos que representan la Unidad Popular y la dictadura militar (1970-1988) a fines de los gobiernos de la Concertación en el cambio de siglo". Santiago de Compostela: XIV Congreso de Latinoamericanistas Españoles: 1653-1673.

.2011. "Cineastas al rescate de la memoria reciente chilena." Imagofagia 4.

Burke, Peter 2005. Visto y no visto. El uso de la imagen como documento histórico. Barcelona: Crítica.

Butler, Jeremy 2002. Television. Critical methods and applications. New Jersey: Lawrence Erlbaum-The University of Alabama Press.

Cabalin, Cristian y Ricardo Ramírez 2015. "Haciendo historia de uno/a mismo/a: construcción de memorias en espectadores/ as de Los 80." Audiencias volátiles. Televisión, ficción y educación. Antezana. L. y Cabalin, C ed. Santiago de Chile: Instituto de la Comunicación e Imagen: 54-70

Camarero, G., De las Heras, Beatriz, de Cruz, Vanessa 2008. Una ventana indiscreta. La historia desde el cine. Madrid: Ediciones JC.

Caparrós, José María. "Enseñar la historia contemporánea a través del cine de ficción". Quaderns de cine 1 (2007): 25-35.

Cartmell, D., Hunter, I.Q., Whelehan, I. 2001 (eds). Retrovisions. Reinventing the Past in Film and Fiction. Londres: Pluto Press.

Castillo, Ana María, Simelio y Solá, Nuria, Ruiz, María Jesús 2012. "La reconstrucción del pasado reciente a través de la narrativa televisiva. Estudio comparado de los casos de Chile y España." Revista Comunicación 10 (2012): 666-681.

Chicharro, María del Mar 2009. "Información, ficción, telerrealidad y telenovela: algunas lecturas televisivas sobre la sociedad española y su historia," Nueva época 11: 73-98.

Del Alcázar, Joan 2013. Chile en la pantalla. Santiago: DIBAMUniv. De Valencia.

Durán, Jean-Stéphane 2008. "Televisión contra memoria. Uso y abuso de la historia en la televisión franquista." Historia y Comunicación social 13: 33-45.

Erlij, Evelyn 2014. "Escribir el pasado con el Lente de una Cámara: el Cine como Documento Histórico." Comunicación y Medios 29: 76-91. Akal.

Ferro, Marc 2008. El cine, Una visión de la historia. Madrid:

Fiske, John 2001. Television Culture: popular pleasures and politics. Londres: Routledge.

Fiske, John, Hartley, John 2004. Reading televisión. Londres: Taylor \& Francis.

González Requena, Jesús 1995. El discurso televisivo.
Espectáculo de la posmodernidad. Madrid: Cátedra.

Guynn, Willyam 2006. Writing history in film. Londres-Nueva York: Routledge.

Hartley, John 2008. Television Truths. Massachusetts: Blackwell, 2008.

Holland, Patricia 2000. The Television Handbook. Nueva York: Routledge, 2000.

Jablonska, Aleksandra 2009. Cristales del tiempo. Pasado e identidad de las películas mexicanas contemporáneas. México: Universidad Pedagógica Nacional.

Jakubowicz, E., Radetich, L. 2006. La historia argentina a través del cine 1933-2003. Buenos Aires: La Crujía.g

Jarpa, Guillermo 2017. "Recuerdos a colores: una exploración al dispositivo moral y televisivo desarrollado en la primera temporada de Los 80". Coloquio Discursos históricos en la ficción televisiva chilena. Universidad de Chile.

Laguarda, Paula 2006. "El cine como fuente y escritura de la historia". Anuario de la Facultad de Ciencias Humanas de la Universidad Nacional de la Pampa 8: 109-119.

Llorens-Maluquer, Carles 1998. "La convergencia estructural entre las empresas de telecomunicaciones y del audiovisual." Zer - Revista de Estudios de Comunicación 5.

Martín-Barbero, Jesús 1991. De los medios a las mediaciones. Comunicación, cultura y hegemonía. México: Gustavo Gili.

Mateos, J., Ochoa, G. 2016. "Contenido y representación de género en tres series de televisión chilenas de ficción." Cuadernos. info 39: 55-66.

Metz, Christian 1970. "El decir y lo dicho en el cine: ¿hacia la decadencia de un cierto verosímil?" VV.AA. Lo verosímil. Buenos Aires: Tiempo Contemporáneo: 17-30.

Miranda, Christian 2010. "La transformación del relato cinematográfico y televisivo en la representación del pasado." Analecta Revista de Humanidades 4: 1-22.

Monterde, J., Selva, M. y Solá, A. 2003. "La representación cinematográfica de la historia." FilmHistoria 13 (1).

Mujica, Constanza 2007. "La telenovela de época chilena: Entre la metáfora y el trauma." Cuadernos de Información 21: 20-33.

Nigra, Fabio (coord.) 2010. Hollywood: ideología y consenso en la historia de Estados Unidos. Buenos Aires: Maipue.

Nigra, Fabio (coord.) 2012. Visiones gratas del pasado. Hollywood y la construcción de la Segunda Guerra Mundial. Buenos Aires: Imago Mundi.

Otero, E., López, R. 1993. Televisión y violencia. Santiago: Bravo y Allende Editores.

Pelaz, José-Vidal 2007. "El pasado como espectáculo: reflexiones sobre la relación entre la Historia y el cine". Légete 7: 5-31.

Piccinelli, Mariana, Dadamo, Florencia y Della Mora, Leandro 2012. "Cine e historia en la Argentina: un estado de la cuestión". Esboços 27: 171-195.

Ranaletti, Mario 2001. "El cine frente a la memoria de los contemporáneos. Historia y memoria en la Argentina sobre el terrorismo de estado a partir de dos películas de Andrés Di Tella." 
Historia Contemporánea 22: 81-95.

Raurich, V. Silva, J.P 2011. "La exhumación de lo premoderno: la imagen de los pueblos originarios en el cine de ficción y documental chileno". Estudios sobre las culturas contemporáneas 34: 65-83.

Rinke, Stefan. Cultura de masas: reforma y nacionalismo en Chile 1910-1931. Santiago: DIBAM, 2002.

Rodríguez, Maria de los Ángeles 2004. "Contemporary Hi(stories) of Mexico: Fictional Re-Creation of Collective Past on Television." Film \& History: An Interdisciplinary Journal of Film and Television Studies, 34 (1): 49-55.

Romano, Silvia 1998. "Los documentos audiovisuales como fuentes de la historia. Un estudio preliminar". Estudios Sociales 15: $227-241$.

Romero, David (Ed.) 2002. La historia a través del cine. Memoria e historia en la España de la posguerra. Bilbao: Universidad del País Vasco.

Rosenstone, Robert 1997. El pasado en imágenes. El desafío del cine a nuestra idea de la historia. Barcelona: Ariel.

Rubio, Coro (ed.) 2010. La historia a través del cine. Estados Unidos: una mirada a su imaginario colectivo. Bilbao: Universidad del País Vasco.

Rueda, José Carlos 2009. "La historia televisada: una recapitulación sobre narrativas y estrategias histioriográficas." Comunicación y sociedad 12: 177-202.

Rueda, J. C, Chicharro, M. D. 2004. "La representación cinematográfica: una aproximación al análisis sociohistórico." Ámbitos 11-12: 427-450.

Ruzafa, Rafael (ed) 2004. La historia a través del cine. Transición y consolidación democrática en España. Bilbao: Universidad del País Vasco.

Salaverría, Ramón 2010. "Estructura de la convergencia." Convergencia digital. Reconfiguración de los medios de comunicación en España. López, X.,Pereira, X. (eds). Santiago de Compostela: Servicio Editorial de la Universidad de Santiago de Compostela: 27-40.

Salinas, C., Stange, H.,y Santa Cruz, E. 2013. "Apuntes para la discusión de la relación cine-historia en la cinematografía chilena de ficción." Revista Austral de Ciencias Sociales 25:115-127.

Salinas, C., Stange, H. (eds) 2017. La mirada obediente. Historia nacional en el cine chileno. Santiago: Universitaria. 2018. "La historia en tiempo presente.
Fascinaciones televisivas con el pasado de Chile". Análisis crítico del discurso: teoría y práctica. del Valle, C (ed.). En prensa.

Santa Cruz A., Eduardo 2018. "La producción mediática de la Guerra del Pacífico (del folletín a las series televisivas)". Mapocho 83 (2018).

Scolari, Carlos A., et al. 2012. "Narrativas transmediáticas, convergencia audiovisual y nuevas estrategias de comunicación." Quaderns del CAC 38: 79-89.

Sojo Gil, Kepa 2009. "La representación de la historia en el cine. A propósito de Kingdom of Heaven (El Reino de los Cielos, 2005), de Ridley Scott y las películas de cruzadas en la historia del séptimo arte." Clio \& Crimen 6: 278-295.

Sorlin, Pierre 2005. "El cine, reto para el historiador." ISTOR 20: $11-45$.

del mañana. México: FCE.

Tal, Tzvi 2012. "Memoria y muerte. La dictadura de Pinochet en las películas de Pablo Larraín: Tony Manero (2007) y Post Mortem (2010)," Nuevo Mundo Mundos Nuevos (en línea) https:// journals.openedition.org/nuevomundo/62884

Tranchini, Elina 2011. "Cine e historia: Visiones fílmicas de la Revolución Rusa. Desde su conmemoración hasta la Guerra Fría y después del colapso." PolHis 8: 140-151.

Uroz, José (ed.) 1999. Historia y cine. Alicante: Universidad de Alicante.

Vásquez, David 1986. "El cine como registro de una sociedad de cambia". Chile. Historia y presente. Una visión interdisciplinaria. Riquelme, A. (ed.). Santiago: Pontificia Universidad Católica de Chile: 119-ss.

Vilches, Lorenzo 1993. La televisión: los efectos del bien y del mal. Barcelona: Paidós.

1997. La lectura de la imagen. Prensa, cine, televisión. Barcelona: Paidós.

White, Hayden 2010. Ficción histórica, historia ficcional y realidad histórica. Buenos Aires: Prometeo Libros.

Williams, Raymond 2011. Televisión. Tecnología y forma cultural. Buenos Aires: Paidós.

Wolf, Mauro. La investigación de la comunicación de masas. Crítica y perspectivas. Barcelona: Paidós, 1985.

Wolf, Mauro 1992. Los efectos sociales de los media. Barcelona: Paidós.

Zunzunegui, Santos 2002. Pensar la imagen. Madrid: Cátedra. 